\title{
Morphological and clinical picture of the morphea in the oral cavity
}

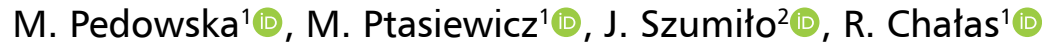 \\ ${ }^{1}$ Department of Oral Medicine, Medical University of Lublin, Poland \\ 2Department of Clinical Pathomorphology, Medical University of Lublin, Poland
}

[Received: 15 July 2021; Accepted: 4 August 2021; Early publication date: 24 August 2021]

\begin{abstract}
There are several types of morphea with different levels of connective tissue involvement and morphological manifestations.

In this mini review, it was pointed out the most important morphological and clinical aspects of localised scleroderma in the oral cavity. The case presented in this article supports the scientific information and is described with details. The morphea of mucous membrane which was clinically suspected, was proved by histopathological examination of the sample.

The unusual location of the local findings posed a diagnostic challenge. The case history should be significant due to the low number of studies. The special attention should be taken to match the clinical with pathomorphological picture in localised scleroderma diagnosis and treatment when the involvement of skin and oral mucosa is. (Folia Morphol 2022; 81, 3: 544-550)
\end{abstract}

Key words: linear scleroderma, oral cavity, oral mucosa

\section{INTRODUCTION}

Scleroderma is the disease of connective tissue which primarily affects the mucous membrane or skin with their thickening and hardening. There are two types of scleroderma listed in the literature: the first type is morphea - localised form and the second type is systemic sclerosis or systemic scleroderma [5].

Morphea is a disorder which generally affects skin but may also influence the muscles and bone structure. The systemic sclerosis mostly involves the internal organs, such as the heart, oesophagus, kidneys and lungs. The severity and outcomes of systemic scleroderma vary. Microscopic appearance of scleroderma depends on the stage of the disease. For a correct histopathological diagnosis, the skin sample should contain subcutaneous tissue, what is related to the fact that morphological anomalies are best visible in the transition area between the dermis and the subcutaneous tissue.

Early lesions are difficult to diagnose. Clinically, they are described as discoloured, pale macula. Histology is not characteristic. In the early stage of the disease, periadnexal and perivascular lymphohistiocytic inflammatory infiltration is found histologically, as well as a denser, homogenized collagen. In the area of blood vessels, this collagen is more eosinophilic. This is the cause of periadnexal fat reduction or disappearance. The collagen formed at this early stage can penetrate into adipose tissue as pseudopods and may be followed by an inflammatory infiltrate. A tumefied endothelium with decreased lumen may be visible on dermis and subcutaneous tissue [15].

More advanced stages show no clinical signs of inflammation, but the fibrosis of the dermis is evident and progressively spreads over the adipose tissue.

Address for correspondence: Prof. R. Chałas, Department of Oral Medicine, Medical University of Lublin, ul. Dra Witolda Chodźki 6 20-93 Lublin, Poland, e-mail: renata.chalas@umlub.pl

This article is available in open access under Creative Common Attribution-Non-Commercial-No Derivatives 4.0 International (CC BY-NC-ND 4.0) license, allowing to download articles and share them with others as long as they credit the authors and the publisher, but without permission to change them in any way or use them commercially. 
The histological pictures and diagnosis of more advanced lesions are more foreseeable. At this stage, the dermal collagen is eosinophilic and homogenized. There is no inflammatory infiltrate that already shows atrophy. The vessels of the subcutaneous tissue show a thickened wall and significantly decreased lumen size. The destruction of adipose tissue clinically manifests as the depression of the skin and replacement of adipose tissue by sclerotic collagen is best visible when compared with a contralateral normal skin [5].

\section{Aetiology and pathogenesis}

The aetiology of scleroderma is not fully known. Some environmental factors like silica or organic solvents may play an important role. It may be also triggered by viral or bacterial (Borelia burgdorferi) infections [14].Genetic factors have been also implicated [1]. Some forms of morphea are activated by trauma or associated with an autoimmune process.

The pathogenesis of localised and systemic scleroderma appears to be similar and complex. It may involve such syndromes as the facial tissues and the ipsilateral brain parenchyma, which contains progenitor cells. The proposed explanation for cortical dysgenesis as a cause of scleroderma development is put forward. It is a developmental defect that affects the rostral neural tube unilaterally. It is sometimes characterised as a neurocutaneous syndrome in which cutaneous manifestations are strictly connected with primary brain malformations.

A clone of vulnerable cells would develop lesions following the Blaschko's lines. According to these hypothesis there is a possibility that genetic mosaicism is a determining factor for the linear distribution of the sclerosis process. This theory would explain why multiple frontoparietal lesions are observed [2].

Since some skin lesions are seen on the area supplied with trigeminal nerve branches, the disruption of sympathetic fibres is also regarded as an aetiological factor [16]. Overall, inflammation with probable autoimmune factors and embryological disease such as genetic mosaicism appears to be more clearly associated with localised scleroderma aetiopathogenesis.

Three primary mechanisms contribute to the development of scleroderma: autoimmune phenomena, excess fibrosis and vascular anomalies. Those anomalous interactions between endothelial cells, fibroblasts, and lymphocytes ( $B$ and $\mathrm{T}$ ) lead to microcirculatory vascular involvement. The endothelial cells generate great amounts of endothelin 1, causing vasoconstriction and fibroblast activation. Furthermore, fibroblasts and activated endothelial cells produce reactive oxygen species that accelerate vascular remodelling, leading to obliteration of small vessels. Activated fibroblasts readily differentiate into myofibroblasts, which have an increased ability to synthesize collagen [3].

\section{Epidemiology}

Scleroderma is not a common disease. Its prevalence varies according to gender, ethnicity and geographical area. Although systemic scleroderma is rare in children and the elderly, it can occur at any age. The disease is most common in people aged $30-50$ years. As with many other autoimmune diseases, women are at greater risk than men ( $\mathrm{F}: \mathrm{M}=4.6: 1)$. Taking the United States as an example, the overall incidence rate among adults is approximately 20 per million per year. This rate has increased between 1944 and 1973 , but has been relatively stable since that time.

Localised scleroderma is relatively rare with around 0.3 to 3 cases per 100,000 inhabitants annually. Prevalence is similar in children and adults. Ninety per cent of children are diagnosed between the ages of 2 and 14, whereas for adults the peak incidence is in their fifth decade. It is more common in Caucasian women (F:M = 2-4:1) [23].

\section{Morphea}

There are several subtypes of morphea distinguished in the literature with different clinical manifestations and levels of connective tissue involvement. Each subtype may affect the face with varying intensity. Subtypes are not exclusive, different ones may be seen in the same patient. The subtypes may transform and coexist [15].

The most widely used classification of morphea is Mayo Clinic Classification [23], which distinguished: generalised morphea; plaque morphea; bullous morphea; linear scleroderma - with subtypes involving the head and face, linear scleroderma "en coup de saber", progressive facial hemiatrophy with Parry-Romberg syndrome and deep morphea [17]. Laxer and Zulian include five subtypes of morphea: circumscribed (superficial or deep), linear (superficial or deep), generalised, pansclerotic, or mixed [4]. A group of experts at the European Dermatology Forum proposed a classification of localised scleroderma (LS) that takes into account the extent and depth of fibrosis and includes the main five types as follow: 
1. Limited type; 2. Generalised type; 3. Linear type; 4. Deep type; 5. Mixed type, with some subtypes inside of every group. The authors consider eosinophilic fasciitis (Shulman syndrome) as a separate type within the spectrum of LS [8].

Plaque morphea is the most common form in adults and it is described as well-demarcated oval or round areas of hard and shiny mucous membrane or skin. In the very early stage, a violaceous halo around the plaque ("purple ring") is sometimes observed. It can involve the skin and subcutaneous of several anatomical regions, usually on the trunk and proximal extremities [3]. Bullous type of morphea is rare and it is a mixture of such lesions as: blisters, erosions, and the more common plaques. In deep morphea, a single lesion is observed, usually on the upper trunk, near the spine. The skin over it may look normal, atrophic, or may be hardened with depression. Typically, the dermis, adipose tissue and muscles are affected. Associations with vaccine administration or intramuscular injection of vitamin $\mathrm{K}$ have been reported in some cases [24].

In generalised morphea plaques and spots are observed in more than 2 places on the body. It is more frequent in women than in men. In some cases, exercise has been described as the trigger. Lesions are usually multiple ( $>4$ ), more than $3 \mathrm{~cm}$ in dimension, ill-defined, pigmented, indurated, and adhered to deep planes. Plaques are formed mainly on the trunk and limbs. Hardening is relatively quick within a few months, but no signs of acute inflammation such as swelling and erythema may be observed [13].

Linear scleroderma is described as a linear induration, usually single and unilateral, involving the dermis, subcutaneous tissue, muscle, and underlying bone. The lesions are seen mostly on the extremities, face, or scalp. They often follow Blaschko's lines. Growth disturbance and ankylosis may be found in cases in which muscles and bone are affected. Close to $67 \%$ of patients with linear scleroderma are children before 18 years of age. It affects males and females equally. In almost one-half of patients with linear scleroderma, a combination with another subtype of localised scleroderma is observed - so-called mixed morphea. Localised facial scleroderma associated with linear sclerosis or plaque morphea elsewhere (most often on the torso) is typical for children. Changes located on the scalp can cause alopecia with a linear distribution and the affected area is often atrophic or depressed. The skin which covers the lesion is smooth, shiny, hard, and sometimes pigmented. It tends to deform the bone and it is usually unilateral, affecting the parietal region. It can extend to the cheek and nose areas as well as the upper lip [6].

Linear scleroderma "en coup de sabre" is a slowly progressive disease limited to the hemiface. In this type of scleroderma, stiffness and contractions of the affected area are noticeable first, followed by the area of linear alopecia, extending from the parietal area to the scalp. The depressed area/line often covers the area of the upper lip and nose, even reaching to the gingiva, spacing and changing the position of the teeth. Sometimes the lesions include the maxilla and mandible bones, which results in occlusal abnormalities, delayed teeth eruption or atrophy of roots [18]. Children commonly have this particular form of linear scleroderma, but female individuals are more often affected (F:M = 3:1).

Parry-Romberg syndrome, known as progressive facial hemiatrophy, is a rare disorder. It develops in the first and second decade of life, commonly affects the dermatomes of one or multiple branches of the trigeminal nerve. In the affected areas of the scalp, scarring alopecia, hardening of the skin and changes in its colour, such as depigmentation and hyperpigmentation, may be observed. These changes precede the atrophy of the subcutaneous tissue, skin, muscles and the underlying bone structures. This atrophy is usually unilateral [21]. The disease progresses slowly, becomes self-limited and stationary over time. The process usually takes 2 to 20 years. Progressive facial hemiatrophy may clinically resemble linear scleroderma. They may coexist in approximately $20-37 \%$ cases. In most cases, dermatitis and hardening of the skin are minor or absent, usually below the eye region. Linear scleroderma and progressive facial hemiatrophy are sometimes regarded as a spectrum of the same disease [7].

\section{Introduction to the clinical presentation}

Morphea is a form of linear scleroderma which can involve the head and neck region. The disease results in excessive deposition of collagen, sclerosis, and atrophy of the involved areas. The lesions may clinically present as hyper- or hypopigmented areas or ivory, atrophic plaques.

The progression of the disease may lead to the damage of skin, subcutaneous tissues, muscles, nerves, and bone resorption [11]. Histopathologic 


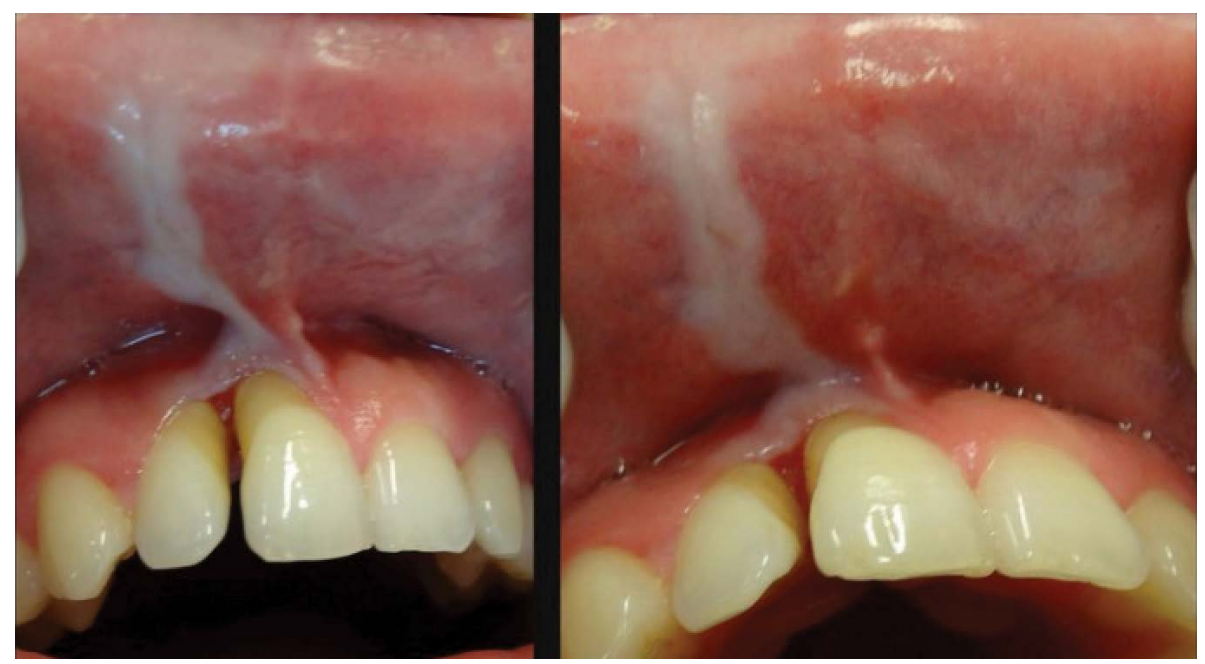

Figure 1. The lesion in the oral cavity before the diagnosis and the treatment. The white, hard, unpainful, unmovable lesion between upper incisors reaching the vestibulum and upper lip.

evaluation usually shows homogenisation and thickening of the dermal collagen, similar to scar formation. Typically, linear morphea has no systemic involvement.

\section{PRESENTATION OF THE CASE}

A 35-year-old military pilot presented in the Outpatient Clinic of the University Dentistry Centre to diagnose a white linear discoloration on the upper alveolar ridge. The patient reported a 6 -month history of the lesion localised between teeth 11 and 12 and the upper lip. The white discoloration was noticed by him while military service in Afghanistan. Later on, the general dentist referred the patient to cover the gingival recessions of teeth 11,12 to a dental surgeon. The clinical and radiological (radiography and cone-beam computer tomography) analysis let to diagnose the bone resorption localised between and above the apexes of the incisors of the $1^{\text {st }}$ quadrant. The dental surgeon advised the bone regeneration and referred the patient for further treatment to the Department of Oral Medicine, Medical University of Lublin. During the clinical examination, the white patch and a white line on the upper lip leading to the vestibulum and teeth 11,12 were noticed (Fig. 1). The pull syndrome was positive, the attached gingivae were missing, roots were exposed 6 and $7 \mathrm{~mm}$. The $1^{\text {st }}$ degree mobility of teeth 11 and 12 was diagnosed, the teeth were checked for vitality, and the test was positive. The bleeding on probing and pocket depth was measured while routine dental examination. There were no signs of gingivitis or

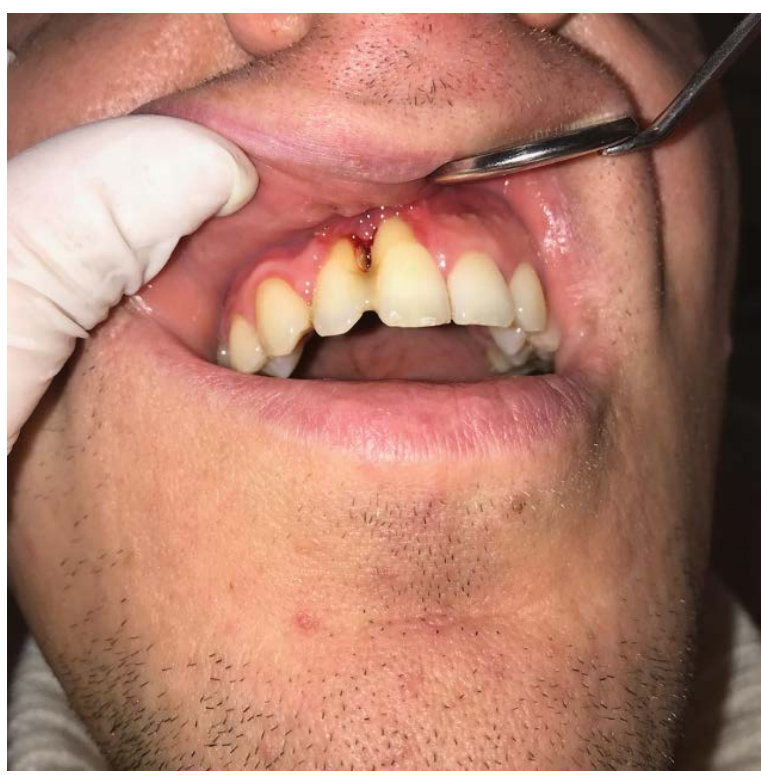

Figure 2. The situation in the oral cavity after the biopsy and the dental treatment. The lesion has been removed for the biopsy, the healing process and scaring is visible.

periodontitis diagnosed in the oral cavity. The patient was referred to the general practitioner and rheumatologist to check-up. The blood tests were without significant changes. The unusual location of the local findings posed a diagnostic challenge. Discolorations continue to progress and the morphea was clinically suspected. The biopsy of the lesion was performed (Fig. 2). Histopathologic evaluation revealed atrophic, partly hyperplastic stratified squamous epithelium and dense, homogenised, deeply penetrating collagen bundles (confirmed by van Gieson stain) with 
A

B

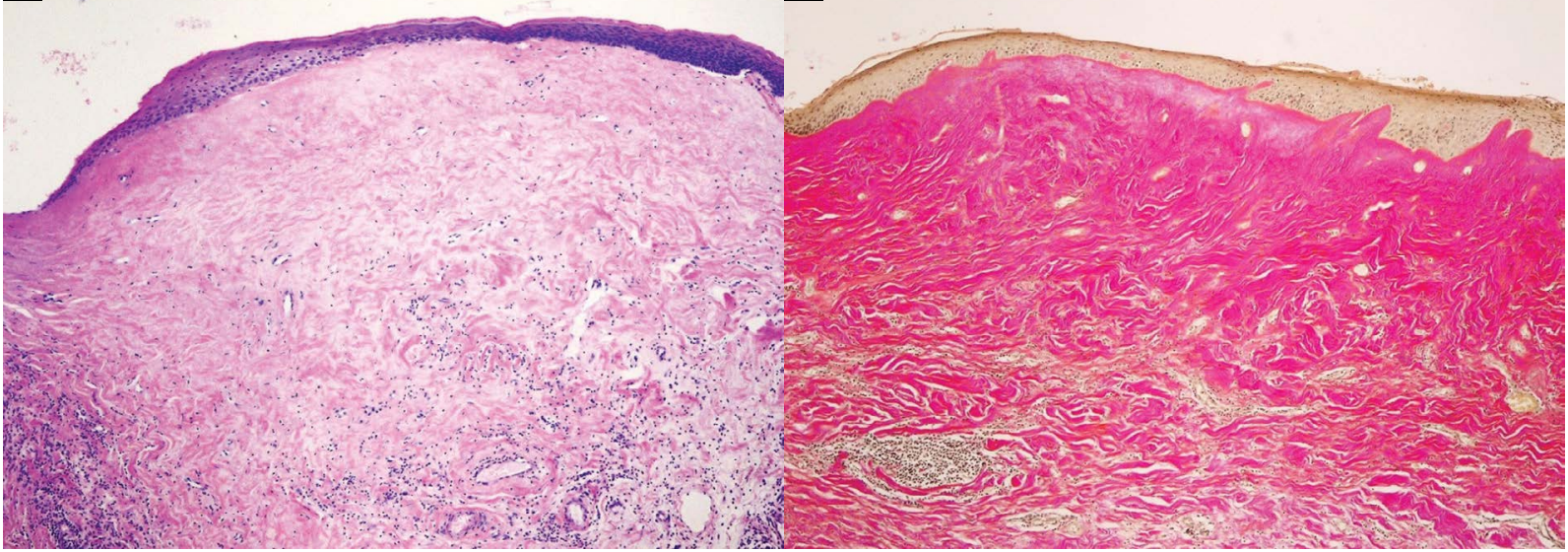

Figure 3. A. Microscopic appearance of the oral morphea. Dense, homogenised collagen bundles with small number of fibroblast and sparse, dispersed and perivascular lymphocytic infiltration in the deeper part of the mucosa; haematoxylin and eosin stain; objective magnification $5 \times$;

B. Microscopic appearance of the oral morphea. Dense, homogenised collagen bundles with small number of fibroblast and sparse, dispersed and perivascular lymphocytic infiltration in the deeper part of the mucosa; van Gieson stain; objective magnification $5 \times$.

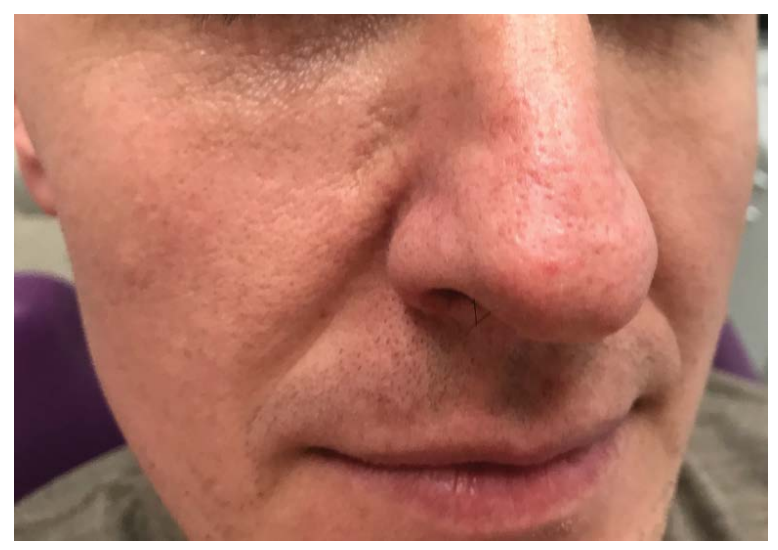

Figure 4. Coexisting lesion on the skin of the cheek before the treatment. The flat, hard, hyperpigmented lesion on the skin of the cheek. Based on the clinical examination the lesion is qualified as the progression of the morphea.

a small number of fibroblasts and sparse, dispersed and perivascular inflammatory infiltration composed mostly of lymphocytes located in the deeper part of the lesion (Fig. 3A, B). After the results of the biopsy, the diagnosis of linear morphea was confirmed.

Due to the toothache of teeth number 11,12 and the progressing mobility of the incisors, the root canal treatment was performed and the teeth were splinted. The intraoral lesion was treated with $0.1 \%$ tacrolimus ointment under occlusive dressing applied twice per day topically. The treatment was administered for 4 months. The patient was observed on control visits every 2-3 months. During the therapy, the intraoral lesion was reduced and softened. After 2 years of observation, a new plaque-like, hyperpig-

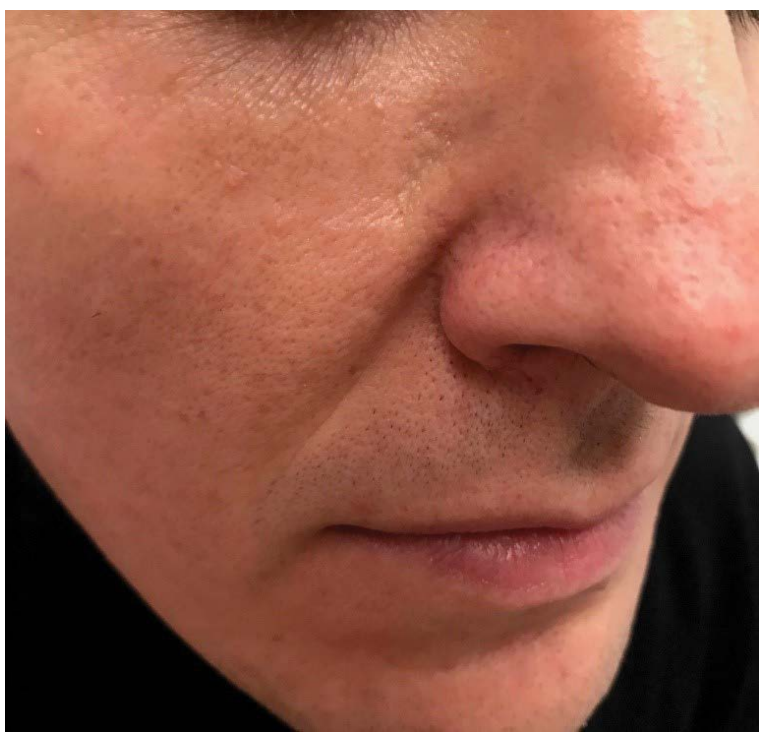

Figure 5. Coexisting lesion on the skin of the cheek after the 8 weeks of the topical tacrolimus therapy. The lesion is limited after local treatment, became softer in palpation and paler.

mented lesion, located on the right side of the nose was observed (Fig. 4). The patient was referred to the dermatologist, the topical treatment of the lesion with the use of $0.1 \%$ tacrolimus was continued. The lesion reduced the size and pigmentation after 3 months of local treatment (Fig. 5).

The patient is under periodontal and dermatological control, and the teeth localised in the lesion are still functioning without mobility. Further dental treatment will be focused on possible tissue and bone regeneration with the use of autogenic growth factors and stem cells. 


\section{DISCUSSION}

Localised scleroderma is a rare disorder of the immune system and connective tissue with unknown aetiology, but environmental triggers, autoimmune phenomena, and genetic factors may contribute a role in the disease development [19]. The disease may attack the skin but also can extend to muscles. It must also be considered regarding local bone loss and gingival recession. Severe course of morphea is a potential cause of deformation and impairment. In almost all cases, the sclerosis process involves the skin alone. Involvement of the oral mucosa and teeth in case of morphea has been rarely reported. Tang et al. [22] in 2012 presented 25 cases described in literature and associated with oral and dental manifestations. Our case with the described symptoms falls into this group too. The differential diagnosis of morphea should include chemical or physical burns and trauma. Initial clinical state can be difficult to diagnose, so the case history is significant. When the lesion is intraoral and affects the gingiva and alveolar ridge, dental care is necessary. Because of the low number of case reports published by now, the careful studying them before early diagnosis can allow to perform proper dental treatment and save the teeth located in the lesion.

At present, there is no agreement how to treat localized scleroderma. Various therapeutic strategies have been presented in the studies based on clinical cases which include: topical or oral vitamin D, D-penicillamine, phenytoin, cyclosporine, corticosteroids, methotrexate and interferon administration as well as psoralen-UVA photochemotherapy [20]. In the initial, inflammatory phase, topical use of strong corticosteroids is recommended. Local treatment is used in cases of more limited and superficial lesions [10]. The efficacy of the treatment of localised scleroderma is difficult to estimate due to the low number of described case reports.

There is no standard modality for the treatment of intraoral scleroderma, either. Topical calcineurin inhibitors such as $0.1 \%$ tacrolimus ointment can effectively reduce skin thickening, hyperpigmentation, hardness, erythema, and contraction. Topical and intralesional corticosteroid therapy, according to the German guidelines applied for 1 or 3 months, has also shown positive effects. Relatively good results were obtained with topical treatment with a vitamin D analogue in combination with phototherapy using low-dose ultraviolet $\mathrm{A} 1$ and $0.005 \%$ calcipotriol ointment applied twice per day [9].

The diagnosis of morphea basis on the rapid and advanced progression of skin lesions. The systemic treatment may be required and drugs of first choice are methotrexate and steroids [12]. Therefore, disease activity and subtype must be assessed before starting treatment.

\section{CONCLUSIONS}

In conclusion, because of unique cases of morphea limited to the oral mucosa, both dentists and medical doctors should be familiar with the clinical presentation of morphea and consider its morphology especially in the presence of isolated whitish lines of plaques of the oral mucosa.

Its proper differentiation and careful observation are important to avoid significant local complications. Most of the patients with intraoral lesions were diagnosed until now in an advanced stage by dermatologists or rheumatologists and not by dentists. Therefore, special attention should be taken to the involvement of skin and oral mucosa in localized scleroderma recognition and treatment.

\section{Conflict of interest: None declared}

\section{REFERENCES}

1. Albuquerque JV, Andriolo BNg, Vasconcellos MRa, et al. Interventions for morphea. Cochrane Database Syst Rev. 2019; 7: CD005027, doi: 10.1002/14651858.CD005027. pub5, indexed in Pubmed: 31309547.

2. Asano $Y$, Fujimoto $M$, Ishikawa $O$, et al. Diagnostic criteria, severity classification and guidelines of localized scleroderma. J Dermatol. 2018; 45(7): 755-780, doi: 10.1111/13468138.14161, indexed in Pubmed: 29687475.

3. Bielsa Marsol I. Update on the classification and treatment of localized scleroderma. Actas Dermosifiliogr. 2013; 104(8): 654-666, doi: 10.1016/j.adengl.2012.10.012, indexed in Pubmed: 23948159.

4. Careta MF, Romiti R. Localized scleroderma: clinical spectrum and therapeutic update. An Bras Dermatol. 2015; 90(1): 62-73, doi: 10.1590/abd1806-4841.20152890, indexed in Pubmed: 25672301.

5. Distler O, Cozzio A. Systemic sclerosis and localized scleroderma - current concepts and novel targets for therapy. Semin Immunopathol. 2016; 38(1): 87-95, doi: 10.1007/ s00281-015-0551-z, indexed in Pubmed: 26577237.

6. Figueiroa Careta M, Romiti R. Localized scleroderma: clinical spectrum and therapeutic update. An Bras Dermatol. 2015; 90(1): 62-73, doi: 10.1590/abd18064841.20152890, indexed in Pubmed: 25672301.

7. Khatri S, Torok KS, Mirizio E, et al. Autoantibodies in morphea: an update. Front Immunol. 2019; 10: 1487, 
doi: 10.3389/fimmu.2019.01487, indexed in Pubmed: 31354701.

8. Knobler R, Moinzadeh P, Hunzelmann N, et al. European Dermatology Forum S1-guideline on the diagnosis and treatment of sclerosing diseases of the skin, Part 1: localized scleroderma, systemic sclerosis and overlap syndromes. J Eur Acad Dermatol Venereol. 2017; 31(9): 1401-1424, doi: 10.1111/jdv.14458, indexed in Pubmed: 28792092.

9. Kreuter A, Krieg T, Worm M, et al. German guidelines for the diagnosis and therapy of localized scleroderma. J Dtsch Dermatol Ges. 2016; 14(2): 199-216, doi: 10.1111/ ddg.12724, indexed in Pubmed: 26819124.

10. Kurzinski KL, Zigler CK, Torok KS. Prediction of disease relapse in a cohort of paediatric patients with localized scleroderma. Br J Dermatol. 2019; 180(5): 1183-1189, doi: 10.1111/bjd.17312, indexed in Pubmed: 30315656.

11. Li S. Scleroderma in children and adolescents. Pediatr Clin North Am. 2018; 65(4): 757-781, doi: 10.1016/j. pcl.2018.04.002.

12. Liu XS, Gao Y, Zheng LiWu, et al. New alternative therapy for orofacial localized scleroderma. Oral Surg Oral Med Oral Pathol Oral Radiol Endod. 2010; 110(3): e15-e19, doi: 10.1016/j.tripleo.2010.04.004, indexed in Pubmed: 20634110.

13. Machan A, Oumakhir S, Khalidi M, et al. Radiation-induced morphea: autoimmunity as a risk factor. Neth J Med. 2019; 77(1): 29-31, indexed in Pubmed: 30774102.

14. Mazori DR, Wright NA, Patel M, et al. Characteristics and treatment of adult-onset linear morphea: a retrospective cohort study of 61 patients at 3 tertiary care centers. J Am Acad Dermatol. 2016; 74(3): 577-579, doi: 10.1016/j. jaad.2015.09.069, indexed in Pubmed: 26892661.

15. Mertens JS, Seyger MMB, Thurlings RM, et al. Morphea and eosinophilic fasciitis: an update. Am J Clin Dermatol. 2017; 18(4): 491-512, doi: 10.1007/s40257-017-0269-x, indexed in Pubmed: 28303481.

16. Noakes R. Assessing the response of morphea and limited scleroderma to tranilast: a small prospective study com- paring topical corticosteroids to a combination of topical corticosteroids and tranilast. Clin Cosmet Investig Dermatol. 2018; 11: 321-326, doi: 10.2147/CCID.S160923, indexed in Pubmed: 30013378.

17. Ozlu E, Karadag AS, Akdeniz N, et al. Morphea secondary to interferon beta $1 \mathrm{~b}$ injection: a case and review of the literature. Dermatol Online J. 2019; 25(4), indexed in Pubmed: 31046913.

18. Rongioletti F, Ferreli C, Atzori L, et al. Scleroderma with an update about clinico-pathological correlation. G Ital Dermatol Venereol. 2018; 153(2): 208-215, doi: 10.23736/ S0392-0488.18.05922-9, indexed in Pubmed: 29368844.

19. Sartori-Valinotti JC, Tollefson MM, Reed AM. Updates on morphea: role of vascular injury and advances in treatment. Autoimmune Dis. 2013; 2013: 467808, doi: 10.1155/2013/467808, indexed in Pubmed: 24319593.

20. Shalaby SM, Bosseila M, Fawzy MM, et al. Fractional carbon dioxide laser versus low-dose UVA-1 phototherapy for treatment of localized scleroderma: a clinical and immunohistochemical randomized controlled study. Lasers Med Sci. 2016; 31 (8): 1707-1715, doi: 10.1007/s10103-016-2041-5, indexed in Pubmed: 27510285.

21. Sommer A, Gambichler T, Bacharach-Buhles $M$, et al. Clinical and serological characteristics of progressive facial hemiatrophy: a case series of 12 patients. J Am Acad Dermatol. 2006; 54(2): 227-233, doi: 10.1016/j. jaad.2005.10.020, indexed in Pubmed: 16443052.

22. Tang MM, Bornstein MM, Irla N, et al. Oral mucosal morphea: a new variant. Dermatology. 2012; 224(3): 215-220, doi: 10.1159/000337554, indexed in Pubmed: 22538799.

23. Tratenberg M, Gutwein F, Rao V, et al. Localized scleroderma: a clinical review. Curr Rheumatol Rev. 2017; 13(2): 86-92, doi: 10.2174/1573397112666160907105434, indexed in Pubmed: 27604889.

24. Vigneron C, Bauer N, Waisse W, et al. Morphée du sein radio-induite : une complication méconnue. Cancer/ /Radiothér. 2014; 18(1): 64-67, doi: 10.1016/j.canrad.2013.09.006. 